MATEC Web of Conferences 17, 01005 (2014)

DOI: $10.1051 /$ matecconf/ 20141701005

(C) Owned by the authors, published by EDP Sciences, 2014

\title{
Study of the Use of Lime Plaster on Heritage Buildings' in Malaysia: A Case Study in George Town, Penang
}

\author{
A.A. Mohamed Sabri ${ }^{1}$, M.Z. Suleiman ${ }^{2, a}$ \\ ${ }^{1,2}$ School of Housing, Building and Planning, Universiti Sains Malaysia, 11800, Penang, Malaysia
}

\begin{abstract}
Awareness of the use of compatible materials in historical building conservation has resulted in a rebirth of lime technology and application. However, knowledge of the preparation of and procedures influencing the final quality of lime is still limited and disagreement regarding the proper use of lime in heritage building conservation still continues to exist. The purpose of this paper is to highlight the reasons for deterioration and to suggest possible treatments for external walls of heritage buildings in George Town, Penang. Since lime has been used on most external walls, it was chosen as the focus of this research. This study was conducted based on a qualitative method which drew upon a review of literature, visual observations, and interviews. From a pilot survey of 85 historical buildings in the core zone, it was found that from the use of lime based materials, the possible defects were caused by three factors: climatic change, air pollution, and maintenance issues. This study focuses on the use of lime plaster as well as issues that could arise from its improper use.
\end{abstract}

\section{Introduction}

George Town, Penang faces several problems when it comes to dealing with issues related to historic buildings. Lack of technical knowledge in repairing and maintaining historic buildings is a major problem, because each stage of repair and maintenance requires a special understanding and analysis of the workings of the building as well as regulations for heritage building conservation [2]. The logical way of proceeding when it comes to the repair of a building goes simply from first noticing the problem to determining the cause, after which, remedies can be prescribed. Hence, it is importance to understand the original materials used and the factors and processes responsible for the deterioration. The selection of a suitable repair method and materials during the conservation of a building can prevent or lessen the effects of the same problems in the future. Lime has been used as a building and decorative material for decades in Malaysia. Lime is a product of calcium carbonate which commonly takes the form of limestone. It is found and quarried in lime stone hills and can also be found in coral, sea shells, and chalk. The conversion to calcium oxide, better known as quicklime, can take place when any form of calcium carbonate is burnt at a temperature between $850^{\circ} \mathrm{C}$ and $1300^{\circ} \mathrm{C}$. Lime is used in walls (lime mortar, lime plaster, lime wash), floors and roofs. Figure 1 details the concept of breathable walls. It shows how lime allows natural ground moisture to move up the wall and to evaporate through lime plaster.

${ }^{\mathrm{a}}$ Corresponding author : mzailan@usm.my

This is an Open Access article distributed under the terms of the Creative Commons Attribution License 4.0, which permits unrestricted use, distribution, and reproduction in any medium, provided the original work is properly cited. 
In order to understand the techniques associated with the use of lime, it is necessary to review its chronological development [3]. It has also been found that the art of using mortar in some form or other is as old as the art of building or as civilization itself. Evidence of the use of mortar exists not only in the older countries of Europe, Asia, and Africa, but also in the ruins of Mexico and Peru. The remains of work by these ancient artisans provide evidence of the enduring qualities of lime mortar as well as the skill and knowledge possessed by ancient craftsmen. A revival of lime mortar application for the repair of historic buildings has taken place due to the recognition of the unfavourable properties of Portland cement mortar, which tends to suffer from problems including brittleness, high strength, and a thermal expansion coefficient which is twice as large as lime mortars and most types of brick and stone [4].

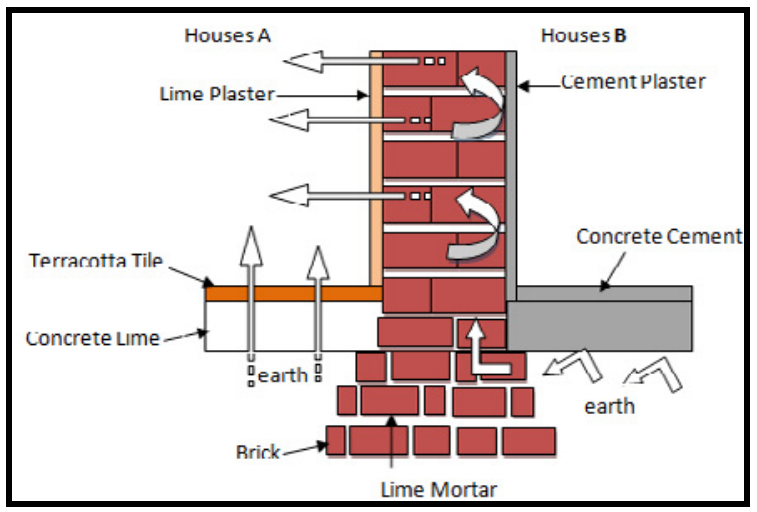

Fig 1:- Moisture evaporation

\section{Methodology}

The study was conducted based on a qualitative method; hence, the data was collected by reviewing related literature, visual observations and interviews. The review of literature was mainly based on published books, research papers, and journals. The types of interviews used in this study included non-structured and focus group interviews. The data that were gathered were based on four main questions:

1. What type of lime was used during the conservation project?

2. What method of lime slaking was used during the conservation?

3. How was the mixture ratio determined?

4. What preparation was needed for the wall?

The duration of data collection was from February 2014 until April 2014. The study area consisted of existing historic buildings in the core zone of the Penang heritage site, where surveys were conducted to collect data on existing wall defects. Only heritage shop houses and colonial buildings were investigated. The estimated number of heritage buildings for the sample size was 170 , which was $10 \%$ of the 1700 buildings in the core zone. To eliminate the factor of bias, simple random sampling was adopted in this study. However, out of the 170 building sampling size, surveys were only carried out to a total of 85 buildings. Data collected from the surveys was analysed using the Glaser and Strauss constant comparative method and then simply summarized in the form of a pie chart.

\section{Results and Discussion}

To ensure that the objective of this study could be achieved, a pilot survey was conducted that targeted heritage buildings in George Town. The pilot survey was used to get a clear understanding of the current conditions of these historic buildings. Figure 2 presents a breakdown of building conditions in George Town, Penang based on visual observations of 85 different structures. From the 
observations, it was found that 53 percent of the buildings were in fair condition, while 35 percent were in good condition and 12 percent were in a dilapidation state.

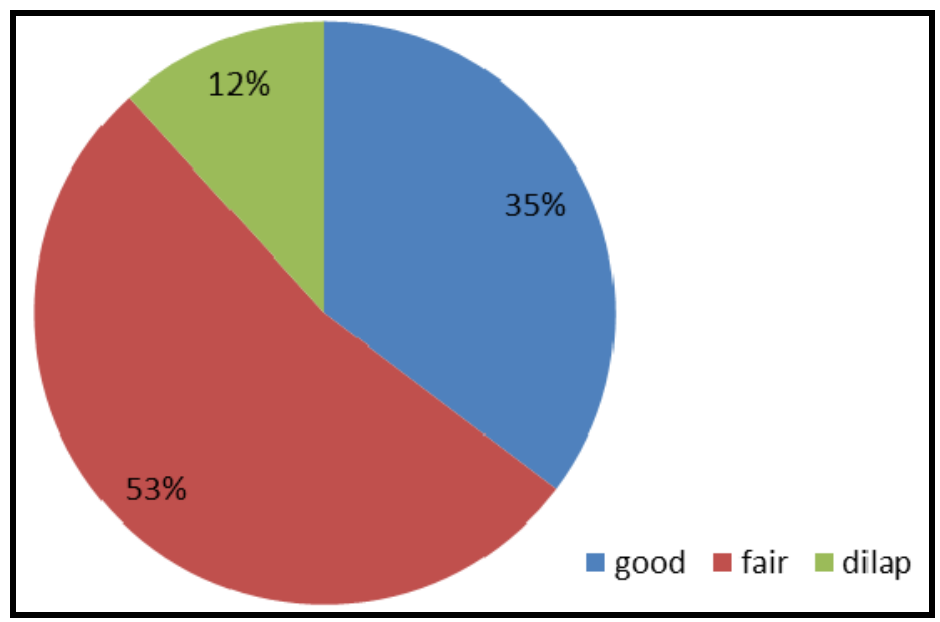

Fig 2: Historic Building Conditions in George Town, Penang.

External walls were chosen as the focus of this evaluation because the façade of each building has an important impact on the image of such a historical district [1]. From Figure 3, nine defects on external walls were identified. Out of 85 selected historical buildings, 75 showed signs of staining, 74 buildings had discolouration, 73 buildings had chalking, 57 buildings suffered from peeling paint, 55 buildings had blistering paint, 46 suffered from non-structural cracks, 35 faced a loss of lime plaster, the mortar of 10 buildings had eroded and 9 buildings suffered from efflorescence.

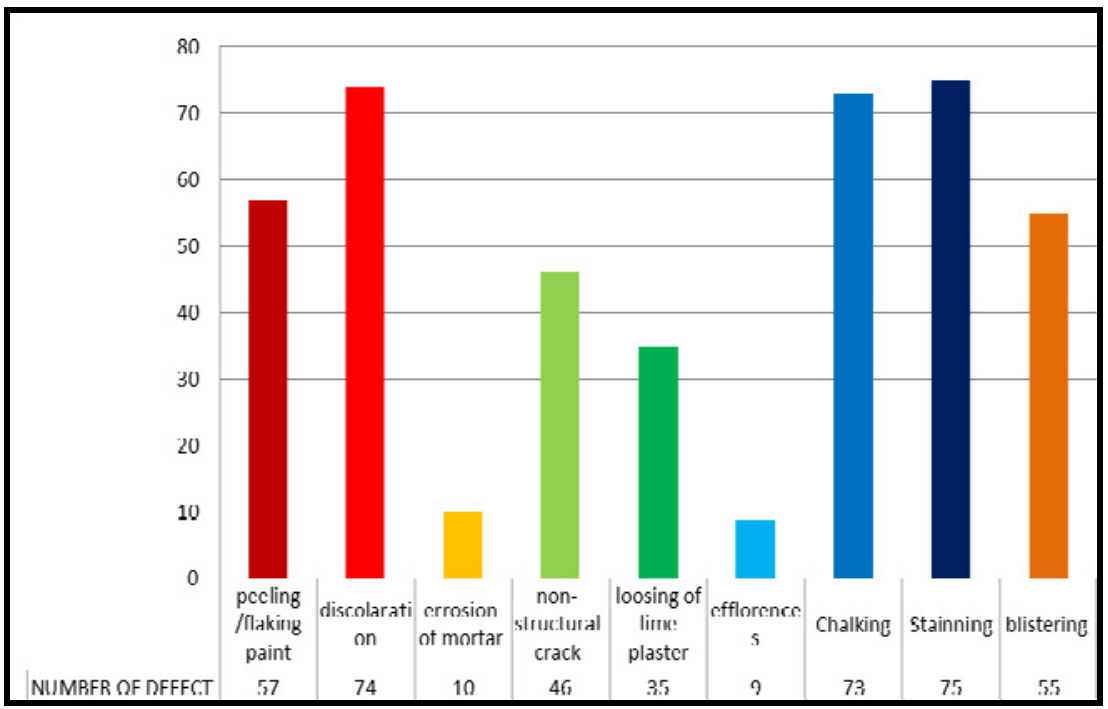

Fig 3: Number of Buildings with External Wall Defects in George Town, Penang World Heritage Site.

Overall, it can be clearly seen from Figure 3 that the most commonly occurring building defects were staining, discolouration, and chalking. The least common defects were erosion of mortar and efflorescence. Plaster is used to protect the brick and to create surface finishes for wall paint. However the use of cement plaster on a wall will trap moisture inside the wall, and after a few years, the plaster will start to crumble and eventually fall off (Figure 4). The same thing will happen to the wall when 
using chemical paint that does not allow the wall to breath. From the site observations, a few buildings were identified that were using incompatible materials. The use of incompatible materials will cause walls to deteriorate. Cement rendering and chemical paint were identified as the main factors contributing to wall deterioration.

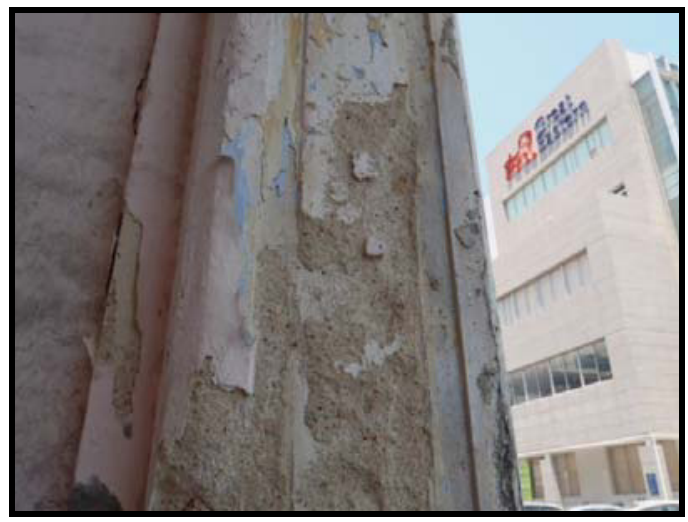

Fig 4: Wall deterioration due to the use of incompatible materials.

The combination of discolouration, chalking, staining, and peeling paint is due to environmental effects. Stains are a type of discoloration produced by foreign substances that have penetrated into the masonry of a building. The result is a chemical reaction between the masonry and the foreign matter. Two types of stains were found from the site observations in this study; these were bio-growth and black crust due to air pollution as shown in Figure 5. The most common stain found was a type of black layer on the external surface caused by vehicle smoke. Stains due to bio-growth are cause by moisture. Surface repainting will not solve both of these stain problems. Moreover, a serious stain problem will lead to damage to the façade in the form of loss of plaster and erosion of mortar.

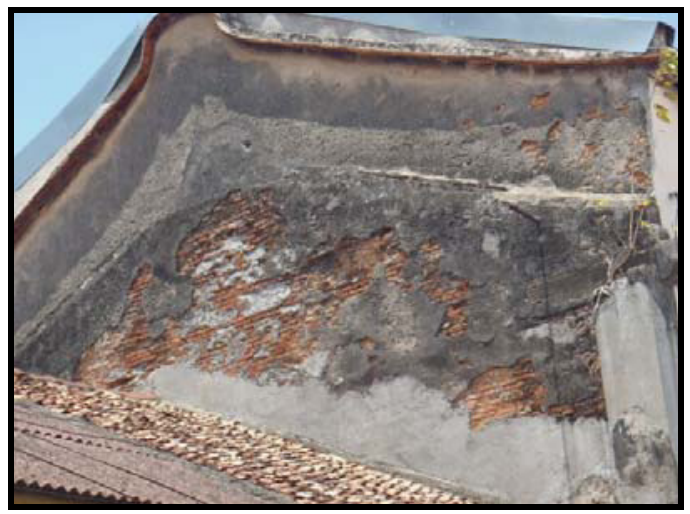

a) Black crust due to air pollution

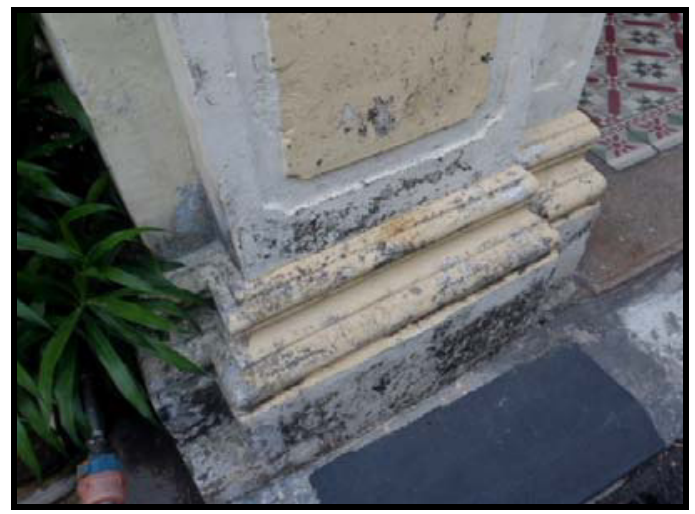

b) Black stains due to bio-growth (algae)

Fig 5: Two types of stains found in George Town, Penang.

Chalking or powdering of the paint surface is caused when resin in the paint film is slowly weakened. The amount of chalking can be determine by the formulation of the paint and the amount of ultraviolet light to which the paint is exposed [6]. Chalking can be considered a way for the paint to "age." Discolouration of paintwork was commonly found in several historical buildings. This was due to the impact of the climate in George Town, Penang. Discolouration also happens when minerals in the paint react with water or chemical cleaners. Peeling paint could be the result of improper surface preparation or due to incompatibility between paint types. As an example, the use of a non-breathable type of paint on a lime plaster surface, such as a chemical paint, will prevent evaporation and the 
excess moisture will lead to wall deterioration (Figures 6 and 7). Paint bulging or blistering is the result of common application errors. It is not likely caused by moisture, but rather, by the reaction of ambient heat on paint. When paint is applied in direct sunlight, the top surface will dry quickly, and, as a result, moisture will get trapped beneath the dried paint. When the moisture vaporizes, it forces its way through the paint film. This problem occurs mostly to dark coloured paint because dark colours absorb more heat than lighter ones.

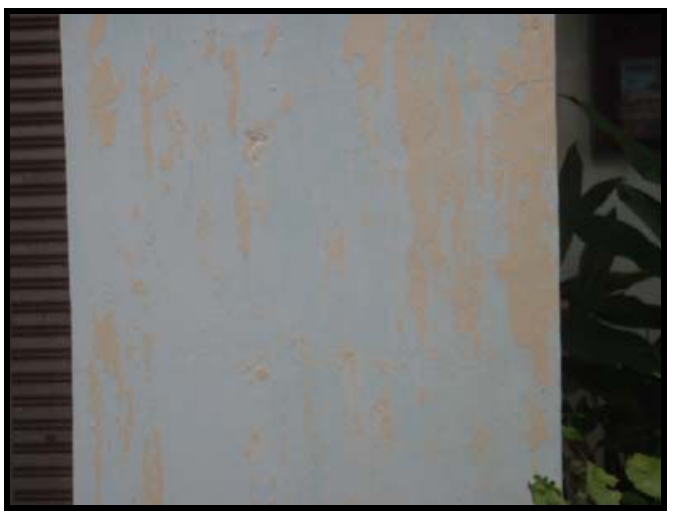

Fig 6: Discolouration on a wall

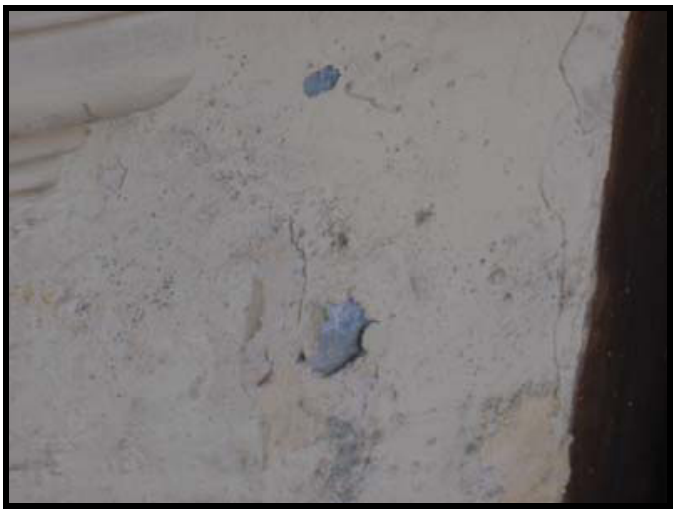

Fig 7: Peeling paint on exterior wall

\section{Repairing the Damage on Heritage Buildings}

According to the data collected, the restoration of external walls can be divided into two categories: remedial for mortar and plaster, and surface remedial. In order to make the necessary repairs with the right materials and techniques, a systematic approach can be used.

Four basic steps can be followed to determine the suitable plaster to be used during the restoration. The first step involves visual analysis and documentation. Next, an experimental study is done, followed by an evaluation. The final step is decision making. Visual analysis and documentation are used to determine the location and causes of defects. The experimental study is composed of two experimental methods (non-destructive and destructive tests). Both tests are used to remove doubt regarding the determination of damage encountered during the visual analysis.

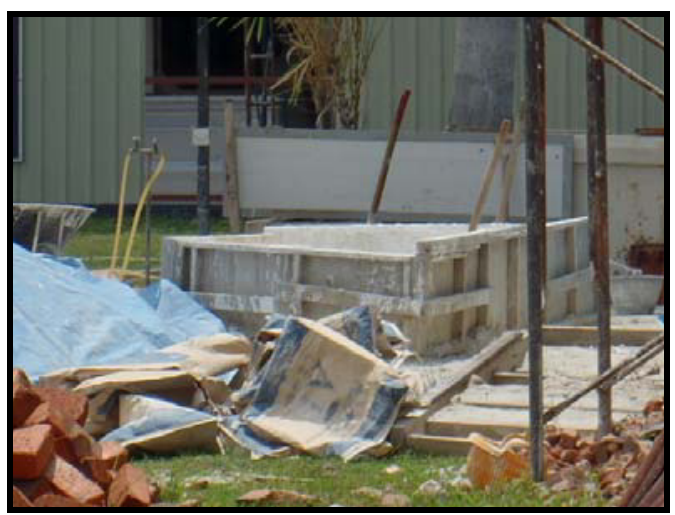

Fig 8: Lime slaking

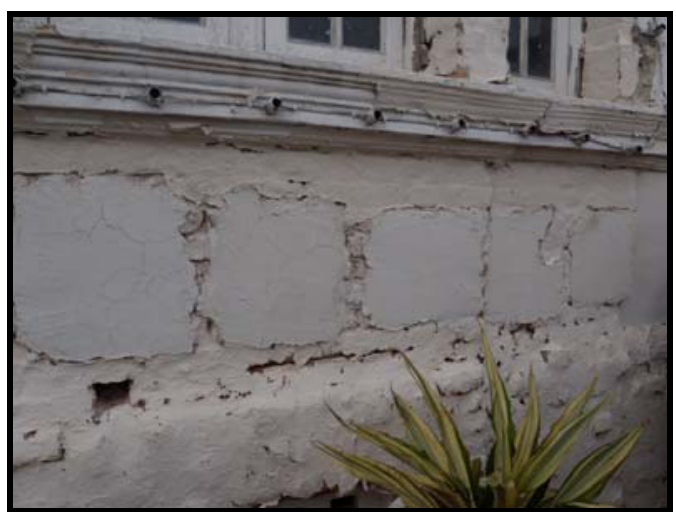

Fig 9: Mock-up sample

A non-destructive testing method, such as using an X-ray Fluorescence spectrometer (XRF), is used to determine the composition of existing materials. Results from the test will determine the main material present in the old plaster and the ratio for the mixture. Having identified the material breakdown, a mock-up plaster needs to be applied according to suggestions for heritage building 
conservation. George Town World Heritage Incorporated (GTWHI) suggests three layers of lime plaster with a ratio of 3:1 (sand and lime). Additional materials also can be added into the mixture to increase the durability of the plaster. Such added materials can be either brick dust pozzolan or Meta kaolin pozzolan. Lime preparation can be done in two ways. The first method uses ready-mix lime putty or powder quicklime. It has been confirmed that several building conservation projects have used powder quick lime that was slaked to form lime putty. To elaborate, the slaking process is done in a large pool of water (lime pit); powdered quick lime is poured into the water and then mixed (Figure 8). Site preparation is crucial when applying lime plaster to a brick wall. The wall needs to be free from any debris and any source of running water. Since building construction is a wet process, walls on which lime plaster will be applied need to be wet. This will help the bonding between the plaster and the wall. Shade needs to be provided during the external application for protection from strong heat [4]. Three coats of lime plaster should build up to a total of $25 \mathrm{~mm}$ consisting of a base coat, a rendering coat, and a finishing coat. All coats will have the same mixing ratio of three parts sand to one part lime. The base coat should have a thickness of 6-10 $\mathrm{mm}$ and should be left to dry for two days before applying the rendering coat. The surface of the base coat needs to be rough in order for the next coat to bond well. The thickness of the rendering coat should be $6-8 \mathrm{~mm}$ and the finishing coat should be 3-4 mm. Figure 9 shows a mock-up sample.

\section{Conclusion}

From the results of the visual observations, it can be concluded that the external factors affecting historical buildings in George Town, Penang are climatic change, air pollution, and lack of proper maintenance. Climate refers to atmospheric events such as rainfall, temperature, air pressure, and humidity. Due to tropical climatic conditions, Penang has heavy rainfall and warm sunshine all year round. Therefore, the external parts of buildings tend to face rapid and harsh exposure to the weather. For example, discolouration of external walls is a common solar effect. Air pollution caused by traffic is also one of the main factors of historical building deterioration. During the visual observations, several buildings were found to suffer from blacking problems. According to Toniolo in 2009, these black carbonaceous particles are also known as black crust. Smoke pollution from vehicles and human activity cause the soiling of facades as black carbonaceous particles are deposited onto buildings' outer surfaces. Such black carbonaceous particles are especially visible on buildings that face the road. Lastly, lack of maintenance is another factor affecting heritage buildings in George Town, Penang. As proper building maintenance plays an important role in preventing defects, poor maintenance or lack of knowledge about how to deal with defects also contributes to the deterioration of a building. It can be concluded that, in order to get effective materials which comply with heritage building restoration regulations, an understanding of the factors causing deterioration and the characteristics of the materials being used is a must. Essentially, each defect affecting a heritage building can be properly repaired and stopped from recurring if the proper treatment is carried out.

\section{References}

1. Askari, A. D. (2009). Influence Of Building Facade Visual Element On Its Historical Image, Case Of Kuala Lumpur Malaysia. Journal Of Design And Built Environment, 5, 49-59.

2. Kamal, K.(2008). Pilot Survey on The Conservation of Historical Buildings in Malaysia.2nd International Conference on Built Environment in Developing Countries(ICBEDC).104-115.

3. Krumnacher, Paul J. (2001) Lime And Cement Technology: Transition From Traditional To Standardized Treatment Method.,Sciences And Technology Studies,1-95.

4. Mold, P. (2005). Limewash: Compatible Covering For Masonry And Stucco. International Building Lime Sympsium, 1-11.

5. Toniolo, L. Z. (2009). Black Layers On Historcal Architecture. Environment Sci Pollut Res, 218226.

6. Weeks, K. L. (1982). Exterior Paint Problem On Historic Woodwork. Preservation Brieefs, 1-11. 